\title{
CIDADE E DIVERSIDADE NO FILME "O CONGRESSO FUTURISTA"
}

\section{CITY AND DIVERSITY IN THE FILM "THE CONGRESS"}

v. 7, n. 2 [11]

ago/dez (2015)

Dossiê

\author{
Marcos Sardá Vieira \\ Universidade Federal da Fronteira Sul (UFFS) \\ marcosarda@gmail.com
}

\section{Resumo}

Esta publicação interdisciplinar apresenta uma reflexão entre o gênero, como categoria de análise, e o espaço, enquanto campo de materialização das representações sociais, dos desejos e da condição do corpo. Em contraste ao planejamento regular e ordenado da cidade do século XIX, como efeito das medidas de controle social, problematizamos a possibilidade de um lugar onde as pessoas pudessem expressar suas singularidades publicamente, indo além do gênero e rompendo com a heteronormatividade. Com apoio da teoria queer, apresentamos o exemplo desta livre associação entre gênero e espaço através do filme "O Congresso Futurista", onde o fluxo das liberdades identitárias, dos desejos e da hibridização do corpo refletem-se na desterritorialização do espaço urbano, definindo o simulacro de um lugar dinâmico e flexível a ser compartilhado.

Palavras-chave: Cidade, Gênero, Queer, Ficção.

\section{Abstract}

This interdisciplinary publication presents a reflection of gender as a category of analysis, and space, while materialization field of social representations, desires and body condition. In contrast to regular planning and orderly city of the nineteenth century, as the effect of social control measures, we exemplify the possibility of a place where people would express their singularities publicly, going beyond gender and breaking with the heteronormativity. With the support of queer theory, we present the example of free association between gender and space through the film "The Congress", where the flow of identity freedoms, desires and body hybridization are reflected in the deterritorialization of the urban space, defining the simulacrum of a dynamic and flexible place to be shared.

Key-words: City, Gender, Queer, Fiction.

\section{Introdução}

A cidade representa os efeitos acumulados da unidade discursiva no espaço, onde se vincula a própria condição da materialização do corpo, das identidades de gênero e dos valores culturais. É neste campo de atuações que a cidade representa os significados de uma consciência corporificada e o resultado da organização do poder de regulamentação do corpo. Questionando a violência da normatividade sobre as questões de gênero, a filósofa Judith Butler (2015a) considera o corpo um fenômeno social que expõe sua vulnerabilidade aos outros, tendo que contar com o que está fora dele para garantir sua sustentabilidade. Por isso, pensar na relação entre gênero e espaço é considerar a possibilidade de (re)organização do lugar, garantindo o agenciamento das relações humanas no processo menos violento e excludente de urbanização, principalmente, em respeito aos corpos humanos não qualificados pela performatividade heterossexual - conceito vinculado aos atos, gestos e desejos presentes 
na superfície do corpo pela expressão da identidade relacionada com a heterossexualidade (BUTLER, 2015b).

Trazendo a relação entre gênero e espaço pela geografia, Rafael Suárez (2015) considera que a violência e o preconceito nas áreas de convivência urbana acontecem devido à constituição da cidade como efeito ampliado do discurso heteronormativo ${ }^{1}$, que contribui para destacar e demarcar a exclusão da diversidade humana no âmbito da cidade inteligível.

Em complemento a perda da diversidade humana, para David Harvey (2015) e Paola Jacques (2005), o predomínio da cidade espetacular padronizada colabora para a eliminação da experiência da alteridade. Relacionando a discussão destes autores, esta perspectiva acompanha as prerrogativas de reforma urbana desde o século XIX e torna a singularidade cultural, geográfica e cotidiana cada vez mais improvável na experiência de um modelo de cidade voltado para os interesses humanos.

A conformação desta realidade urbana pela modernidade ocidental, ao longo dos dois últimos séculos, requereu a intervenção sobre a saúde, a estética e a sexualidade da população citadina. Por isso, a presença dos contrastes sociais, do consenso político e da pasteurização estética refere-se a perpetuação desta concepção, repercutindo nos valores sociais e culturais da contemporaneidade. Principalmente, na maneira como a sociedade se estratifica por hierarquias de classe, de gênero e da própria hierarquia dos corpos, distinguindo entre a regra e a exceção. Esta tradição de valores naturalizados ${ }^{2}$ interfere, diretamente, na disciplina do comportamento, do desejo e das identidades. O que mantém desfavorável a condição de categorias subalternizadas ${ }^{3}$, como as mulheres, os negros, os idosos, os deficientes e as identidades LGBTQ $^{4}$, no desempenho autônomo da experiência urbana.

Mas, por que definir e reconhecer categorias sociais parece algo tão importante e recorrente? Em uma sociedade de comportamentos supostamente livres, não deveria cada pessoa estabelecer sua própria singularidade na prática de sua autonomia política? Em princípio, este questionamento deveria ser confirmado, imaginando um contexto onde cada pessoa se manifesta com relativa liberdade, no direito adquirido do seu corpo e da sua presença na cidade. Entretanto, existe uma grande distância entre o desejo despertado no campo privado e a expressão pública deste desejo através do corpo e de objetos ${ }^{5}$, sem expor a vulnerabilidade intrínseca da exceção diante da regra.

\footnotetext{
${ }^{1} \mathrm{O}$ discurso relativo à heteronormatividade diz respeito ao enquadramento de todas as relações - mesmo aquelas supostamente inaceitáveis entre pessoas do mesmo sexo - em um binarismo de gênero que organiza suas práticas, atos e desejos a partir do modelo do casal heterossexual reprodutivo.

2 No sentido de ser desconsiderado um estado de origem para as identidades de gênero hegemônicas, naturalizadas pela própria reificação da performatividade (BUTLER, 2002).

3 Ou seja, todas as identidades não representadas, ao menos, por uma destas categorias: homem, branco, jovem, eficiente, cis e heterossexual.

${ }^{4}$ Sigla designada para as identidades: lésbica, gay, bissexuais, transgêneros e queers.

5 Objetos como extensões do corpo, que podem estar associados a diferentes escalas: desde roupas e acessórios corporais, tecnologias e equipamentos, passando por veículos e mobiliários, até a escala dos
}

(c) Urbana: Rev. Eletrônica Cent. Interdiscip. Estud. Cid.

Campinas (SP)

v.7, n.2 [11]

p.65-85

ISSN 1982-0569 
Ainda que as relações de poder estejam permeadas por diferenças, como seria um lugar onde as pessoas expressariam suas singularidades livremente, indo além do gênero e extravasando seus desejos e sexualidades? E qual configuração espacial teria este lugar sem previsão de um modelo a ser repetido entre categorias estigmatizantes? Estas perguntas são fundamentais para a reflexão que segue ao longo deste artigo.

No sentido de compreender a importância da diversidade humana no processo político e democrático de significação e materialização das cidades, o gênero torna-se uma categoria de análise crítica, no estudo das dinâmicas sócio-espaciais a partir das relações humanas, definindo um caráter social e cultural para as distinções baseadas no sexo e impostas sobre o corpo sexuado.

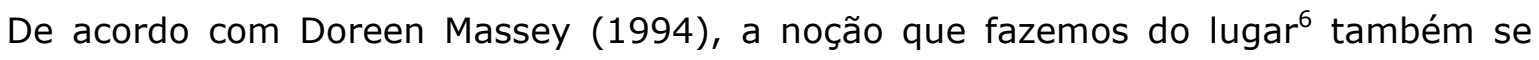
estrutura nas noções de gênero, inserido nas dinâmicas sócio-espaciais de diferentes culturas e ao longo do tempo. O que nos faz considerar que o estado de vulnerabilidade do corpo pela exclusão e/ou adição de identidades, que dão sentido aos efeitos do poder, também está relacionada com os dispositivos urbanos e tecnológicos, permitindo o suporte territorial, material e simbólico para a reiteração performativa e na constituição de indivíduos regulamentados. Regulamentação esta baseada na heteronormatividade, ou seja, na concepção de que a heterossexualidade define a ordem político-social das regulações sexuais e de gênero em nossas vidas (MISKOLCI, 2014). Esta concepção apresenta essência internalizada, como se os gestos, os atos e atuações do corpo estivessem associados a padrões anatômicos e identitários, fixos e estáveis. Aspectos que condicionam a constituição de um modelo de espaço urbano compatível com este contexto de representações sociais.

Questionando esta posição que vê a heterossexualidade como essência do gênero e da sexualidade, a Teoria Queer subverte esta interpretação majoritária da realidade, aceitando a ambiguidade e possibilitando argumentos que não se conformam, diretamente, às regras que o regulam. Assumindo as dissidências, o termo queer engloba, genericamente, a homossexualidade, a transexualidade, a deficiência, a etnia, a intersexualidade, e qualquer sujeito que foge da associação entre gênero, expressão corporal e sexualidade, compatíveis com o perfil heteronormativo. Na interpretação de Guacira Lopes Louro (2009, p. 135) o queer "supõe a não acomodação, admite a ambiguidade, o não lugar, o trânsito, o estar-entre". Enquanto no sentido ontológico, o queer define um sujeito estranho dentro de uma realidade homogênea, padronizada, sugerindo rompimentos na interpretação dominante do que é real.

Como contribuição para as teorias da cidade e na imaginação de uma contrasociedade (CHOAY, 2010), a teoria queer define relações fluídas entre identidades e práticas, que questionam a homogeneização de comunidades através de categorias regulamentadas

edifícios e equipamentos urbanos. A ideia dos objetos associados às transgressões dos significados de gênero e das práticas sexuais é referência na publicação de Paul B. Preciado (2002).

${ }^{6}$ O lugar enquanto espaço concreto e dotado de significação (MASSEY, 2008). 
pela hegemonia heterossexual (SUÁREZ, 2015), apresentando a possibilidade de novos significados para as relações que acontecem no espaço urbano.

Com a intenção de analisar os potenciais de transformação urbana pelo contraste entre a realidade constituída e o pensamento utópico (CHOAY, 2010), este artigo problematiza a adequação estética do corpo e o binarismo da identidade de gênero, no final do século XIX e início do século XX, como justificativa de progresso para a cidade industrial. Em contraste com este paradigma da modernidade e inspirados pela teoria queer, analisamos a narrativa do filme "O Congresso Futurista", relatando a experiência de personagens errantes e figuras singulares através do espaço urbano virtual, simulado através do desenho animado. O cenário ficcional do filme ilustra a perspectiva deste lugar utópico, onde a transgressão com a realidade se faz pela configuração espacial transitória e pela mudança recorrente de identidades e expressões corporais. Neste aspecto indefinido para as categorias de análise, destacamos a importância da arte como subterfúgio crítico e transformador na representação dos potenciais sociais e urbanos através da narrativa visual do filme.

Devido à importância das imagens nesta análise, o texto terá apoio de ilustrações, retratando a cidade de Paris pela a obra de artistas do século XIX e pelas imagens de Nova Iorque apresentadas no filme, aproximando as concepções da modernidade com a ficção cinematográfica futurista, enquanto ideais utópicos, que se distinguem pela diferença de tempo e pela materialidade de suas realizações.

Para a conclusão deste trabalho, consideramos que a profundidade das questões relacionando as temáticas de gênero e espaço é um desafio importante para sairmos da compreensão confortável das categorias reconhecidas. Desta maneira, a discussão sobre a vulnerabilidade social a partir das diferenças do sexo, da orientação sexual e da identidade de gênero torna-se representativa para a redefinição indiscriminada de quem é digno de participar na constituição dos lugares. Agregando os pressupostos da teoria queer nas questões urbanas, consideramos a possibilidade de subverter as relações políticas, econômicas e os significados sociais e culturais hegemônicos pela associação interdisciplinar destes temas, dando chance para a materialização de desejos e afetos em processos mais criativos de configuração urbana.

\section{Estética do Corpo e Disciplina do Gênero na Modernidade}

A cidade corresponde ao dispositivo mais avançado de dominação social dentro da dinâmica do sistema econômico monopolista. De acordo com Rafael Augustus Sêga (2000), a concepção de cidade que alcançamos na atualidade vem se constituindo desde o século XVIII para atender uma demanda econômica liberal.

Este período histórico apresenta importantes avanços na busca pelo progresso da sociedade, de acordo com Anderson Soares Gomes (2011). Ao mesmo tempo, também surgiram questionamentos e comportamentos sociais significativos, que desmistificaram a 
imposição de regras. Por exemplo, apesar dos fundamentos progressistas do Iluminismo estabelecidos por pensadores consagrados como Jean-Jacques Rousseau, John Locke e David Hume, para quem as mulheres deveriam se manter excluídas na tomada de decisões políticas e sociais, também surgem, neste mesmo período, discussões importantes sobre o papel das mulheres e a necessidade de uma educação igualitária. Manifestações pela igualdade de gêneros tornaram-se fatos históricos com a Declaração dos Direitos da Mulher e da Cidadã, apresentado por Olympe de Gouges, em 1791, na França, e a Reinvindicação dos Direitos da Mulher, apresentado por Mary Wollstonecraft, em 1792, na Inglaterra, indo contra os fundamentos sociais de uma imagem essencialista da mulher como um ser da natureza, destinada para os vínculos afetivos como mãe e esposa (GOMES, 2011).

No campo dos desejos e das sexualidades, até o final do século XVIII algumas concessões foram feitas em relação às práticas sexuais nas áreas urbanas, desde que se mantivessem fora dos circuitos oficiais de produção e lucratividade. Segundo Michel Foucault (2014), existia uma preocupação latente com o descontrole dos desejos e das sexualidades quando estas práticas estavam associadas com a maior concentração de pessoas nas cidades. Por consequência, este cenário poderia desencadear menor atenção às frentes de trabalho nas indústrias. No relato de Foucault (2014, p. 29), pela primeira vez na história "uma sociedade afirma que seu futuro e sua fortuna estão ligados não somente ao número e à virtude dos cidadãos, não apenas às regras de casamentos e à organização familiar, mas à maneira como cada qual usa seu sexo". Contra esta razão, na relação entre sexo e poder, surge à possibilidade de transgressão deliberada de resistência, na direta associação da sexualidade com o estado de liberdade (FOUCAULT, 2014).

Na visão de George Simmel (1979), a grande reinvindicação da liberdade individual na vida moderna, já questionada desde o século XVIII, surge pela busca da individualidade diante da pressão da sociedade moderna, da herança histórica, dos valores culturais e dos meios técnicos de vida. Ao mesmo tempo em que o processo de modernização foi idealizado e executado para tornar as cidades mais produtivas, o corpo humano também passou por medidas disciplinares, tornando-se habilidoso e obediente para atender aos interesses de regulamentação das atividades laborais desta nova realidade urbana e industrial. Por isso, a inserção da vida humana neste ambiente civilizado passa a ser vista na condição de um organismo biológico, que poderia ser moldado pelos mecanismos e procedimentos políticos e institucionais, definido por Michel Foucault (2008) como biopoder. Para ele, todas as relações de poder, que permearam e ainda estão presentes em nossa sociedade, acontecem no âmbito do subjetivo, do corpo e do território (FOUCAULT, 2004).

Em complemento a esta ideia, Giorgio Agamben (2002, p. 11) destaca que "o desenvolvimento e o triunfo do capitalismo não teria sido possível sem o controle disciplinar efetuado pelo biopoder, que criou para si, por assim dizer, através de uma série de tecnologias apropriadas, os 'corpos dóceis' de que necessitava". Assim, o cerceamento da conduta 
humana, para atender a um perfil social idealizado, foi justificado para atender ao pleno desenvolvimento da sociedade (FOUCAULT, 2008). Por esta razão, com a consolidação do modernismo e a constituição do espaço urbano, agregando maior número de pessoas nas cidades, estas medidas de controle da biologia e do comportamento humano tenderam a se infiltrar em todos os meios de representação social.

Na visão de Maria Bernardete Ramos Flores (2007), isso não foi diferente entre os movimentos artísticos do final do século XIX e início do século XX, onde surgem denúncias da feminização da cultura, da perda da virilidade masculina e da degeneração racial das nações. Estes indícios colocavam em risco a distinção binária entre homens e mulheres, diante de seus papeis claramente definidos pela estrutura de controle e da lucratividade, prevista para uma sociedade progressista.

Além das distinções entre gênero, raça e a eficiência do corpo, as grandes diferenças sociais tornaram-se nítidas na configuração urbana, pelo modelo de segregação praticado pela cidade industrial. Além do contraste social entre homens e mulheres, ricos e pobres, eficientes e deficientes, por exemplo, o estado de inconsciência na formação de uma unidade social também era mantido sob o controle. Para Richard Sennett (2003) o individualismo e a falta de senso coletivo impediram manifestações a partir de uma tomada de consciência da força coletiva. De acordo com o autor:

As cidades planejadas no século XIX pretendiam tanto facilitar a livre circulação das multidões quanto desencorajar os movimentos de grupos organizados. Corpos individuais que transitam pela cidade tornam-se gradualmente desligados dos lugares em que se movem e das pessoas com quem convivem nesses espaços, desvalorizando-os através da locomoção e perdendo a noção de destino compartilhado (SENNETT, 2003, p. 264).

Além da perda da consciência social, o século XIX marca a grande discrepância das identidades de gênero para as funções sociais. Enquanto ao homem era permitido se empenhar profissionalmente, ser ambicioso e desempenhar papéis em cargos públicos, para a mulher o destino inevitável era o casamento e a maternidade. A expansão dos limites quantitativos, que assinala o crescimento das cidades do modelo orgânico para o mecânico (MUNFORD, 2008), também corresponde ao processo de "mecanização" do comportamento. Ao mesmo tempo em que aparece uma nova ordem espacial para metrópoles europeias como Londres e Paris, são estabelecidos outros valores para o comportamento da população, principalmente, nos espaços públicos. A Figura 1 retrata este lugar de comportamentos e relações dimensionais regulamentados, onde é possível associar a regularidade das ruas e dos edifícios com a disciplina e homogeneidade da representação humana através da expressão do corpo e do gênero, quando presentes no espaço público e espetacular da Paris do século XIX.

(c) Urbana: Rev. Eletrônica Cent. Interdiscip. Estud. Cid. 


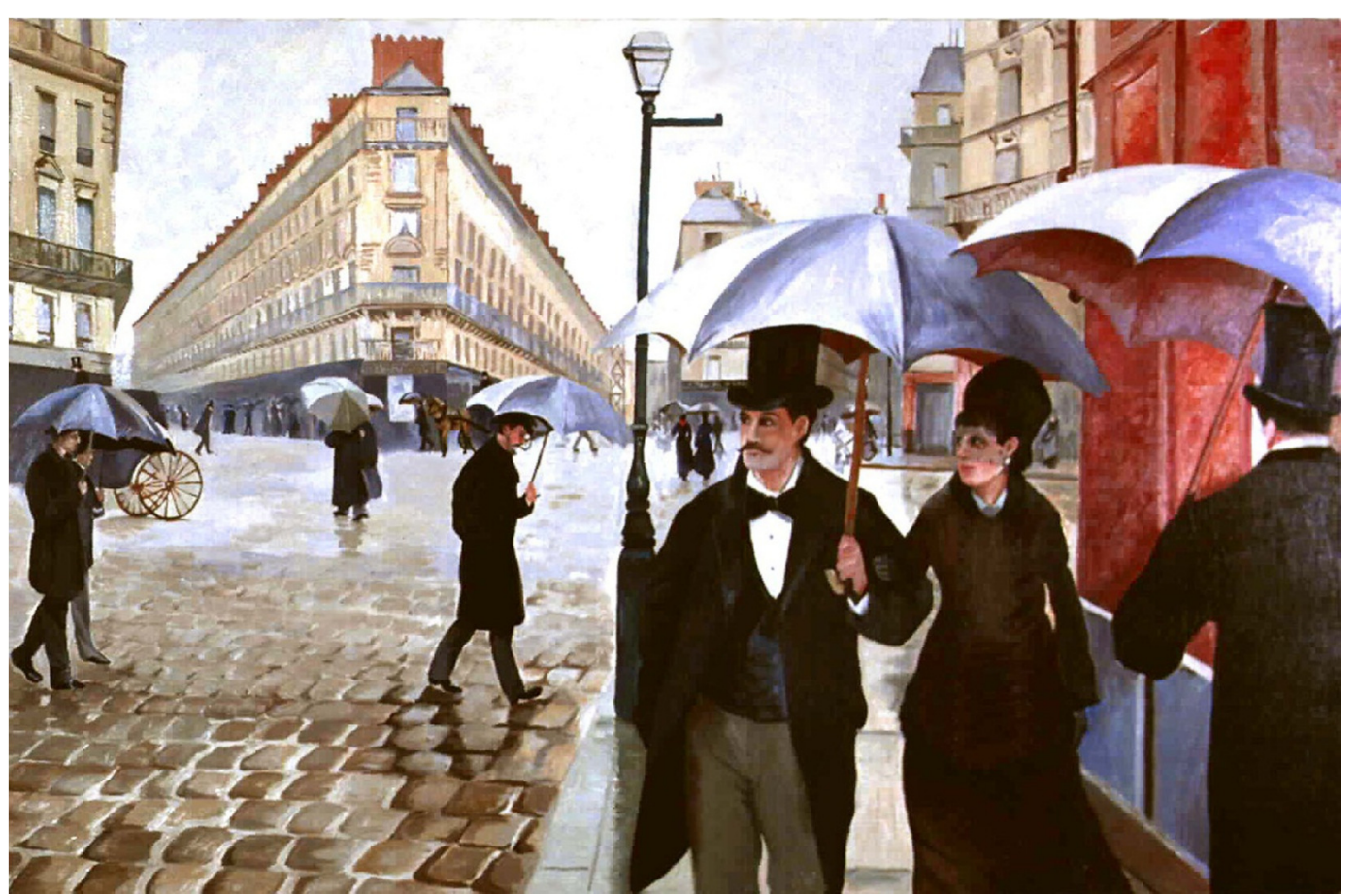

Figura 1 - Rua de Paris em dia de chuva. Pintura de Gustave Caillebotte, 1877. Representação padronizada dos perfis sociais e a distinção das identidades de gênero na estrutura ordenada do ambiente construído.

Fonte: <https://2014saicwiredwed415.files.wordpress.com/2014/09/gustave-caillebotte-paris-streetrainy-day-18772.jpg> Acesso em 03 Abr. 2016.

De acordo com Donatella Calabi (2015), apesar do crescimento vertiginoso das cidades europeias como Londres, Viena e Berlim, na segunda metade do século XIX, foi com a reforma urbana de Paris, entre 1853 e 1870, que surgiu a principal referência de transformação urbana para promover o desenvolvimento econômico, servindo como modelo mundial. Sob o comando do Barão Georges-Eugène Haussman, a reforma da capital francesa estabeleceu os parâmetros da modernidade na paisagem urbana, nos processos de gestão, planejamento e na identidade da população.

Durante a reforma urbana de Paris foram estabelecidas novas relações espaciais para atender ao modelo de cidade modernista, com a intenção de facilitar o consumo nas grandes lojas de departamento e na organização do espaço espetacular para a exposição da vitrine para a rua e no desfile do cidadão consumidor, com seus produtos de consumo, entre roupas, veículos e estilos de vida. As grandes exposições de produtos e inovações tecnológicas representaram a concentração do sagrado neste período, entre artigos e ambientes de consumo, no âmbito focal da cultura urbana (CALABI, 2015; HARVEY, 2015).

Todo este cenário de reformas urbanas serviu como suporte físico para consolidar o poder de comerciantes e especuladores imobiliários, para minimizar a possibilidade de revoltas populares no espaço público e para segregar a população pobre do espaço central da cidade espetacular (HARVEY, 2015, SÊGA, 2000). Inclusive, este modelo parisiense foi exportado para a América Latina, reproduzindo muito mais do que inovações tecnológicas e sistemas

(c) Urbana: Rev. Eletrônica Cent. Interdiscip. Estud. Cid. $\quad$ Campinas (SP) $\quad$ v.7, n.2 [11] $\quad$ p.65-85 ISSN 1982-0569 
construtivos, mas espelhando e redesenhando a idealização do modo de vida e do comportamento da população nos moldes que se formavam na Europa (PESAVENTO, 1999).

Neste período de agonia e romantismo, a ideia de liberdade havia se tornado um discurso de aprisionamento, enquanto o direito à cidade se justificava pela lógica de mercantilização do espaço urbano e pela subordinação do seu valor de uso pelo valor de troca (TRINDADE, 2012). Apesar da configuração deste estado de ordem, permanecia a desordem como efeito simultâneo de crescimento nas principais cidades europeias. A centralidade do planejamento urbano organizado contrastava com espaços sociais periféricos e áreas marginais, frequentadas pelos grupos dissidentes: sujeitos fora da lei, estrangeiros e de comportamentos desviantes. Esse panorama é validado por Foucault (2014) quando afirma que os séculos XIX e XX foram os períodos de multiplicação das sexualidades heterogêneas, com a delimitação de todas as sexualidades periféricas, sua classificação como imorais ou doentes e, ainda, considerando crime a indisposição anatômica de hermafroditas, por exemplo, por não prescreverem a distinção do corpo estabelecida entre os sexos. Neste contexto, a prática da sodomia ao longo da história foi apresentada, nos documentos, com bastante discrição e tratada ora com extrema severidade ou com tolerância, mesmo sendo reconhecidas em sociedades masculinas anteriores, como nos monastérios medievais, nas cortes e no exército. Outro aspecto de distinção das sexualidades desviantes foi a classificação da homossexualidade nos discursos de psiquiatras, médicos, juízes e pensadores do século XIX, o que permitiu um avanço sobre os controles desta nova subespécie humana, que representava a perversidade a ser combatida. Entretanto, esta construção da homossexualidade também trouxe $o$ ato de reinvindicação da sua legitimidade para os movimentos homossexuais que surgiram no século XX (FOUCAULT, 2014).

Mesmo com a repressão à homossexualidade, também surgiram, nesta época, discussões em defesa do amor homoerótico. Por exemplo, em publicações na literatura médico-científica, defendendo o homossexual como ser superior e dotado de potencia criadora; ou pela visão de médicos como Magnus Hirschfeld, requerendo a revogação da lei que penalizava as relações homossexuais, e de Addington Symonds apontando os malefícios clínicos da patologização sexual para os sujeitos homossexuais (FLORES, 2014).

$\mathrm{Na}$ pesquisa sobre a cultura do corpo e da sexualidade, Flores (2007) apresenta os discursos e as tecnologias desenvolvidas no final do século XIX e início do século XX para contemplar o embelezamento e a melhoria de raça humana através de métodos de eugenia praticados pelas políticas dos Estados nacionais. O conjunto de práticas de estetização foi utilizado para modelar o corpo de homens e mulheres, através de medidas racistas para a definição da aparência física almejada para os cidadãos das metrópoles modernas. Em sua pesquisa de dez anos, a autora aponta o envolvimento da medicina, da psicologia, da antropologia e das artes visuais nesta construção teórica e empírica, envolvendo preconceito e

\footnotetext{
(c) Urbana: Rev. Eletrônica Cent. Interdiscip. Estud. Cid.
} 
hierarquia social na valorização de extratos humanos de acordo com a aparência dos corpos ${ }^{7}$. O nacionalismo, enquanto unidade de práticas e discursos para a constituição das nações modernas ocidentais, na segunda metade do século XIX, constitui a chamada era das etnias, onde a formação das nações confundiu-se com a identificação e qualificação das raças, classificadas pela estética do corpo e pelo caráter do indivíduo e do sujeito coletivo. Estes ideais de perfectibilidade da nação, pela regulamentação étnica, representaram a base para as teorias de eugenia praticadas tanto em países democráticos quanto pelos regimes totalitários no início do século XX. Segundo a historiadora:

Neste quadro, insere-se a cultura da etnicidade, na qual o indivíduo se viu contido em sua potencialidade e expansão por estruturas rígidas, instituições disciplinares, governos raciais, para centrar a pessoa do indivíduo numa identidade corporal que se expressasse no sexo, na cor, na classe, na idade, na saúde, na forma e movimento do corpo (FLORES, 2007, p. 65).

Para Flores (2007), a formação da nação moderna também se definiu pelas relações de poder sobre os valores sociais: um fenômeno cultural de intervenção sobre o corpo e o caráter individual para forjar o corpo coletivo como identidade nacional. Dentro do critério liberal da meritocracia, o bem estar e o direito a cidadania passam a depender das capacidades do indivíduo em se adequar ao habitus nacional, impregnando-se dos sentimentos, do idioma, da psicologia, do tipo físico, da prática sexual e da origem dos saberes, a serem inscritas no corpo social como metáfora da nação. "É o corpo que estrutura a narrativa do espaço, selecionando, saltando, agrupando, criando limites, barreiras e fronteiras" (FLORES, 2007, p. 69).

A partir desses referenciais, observamos a apropriação dos corpos sociais na adequação de costumes de uma nova realidade urbana modernista, que se prolonga no século XX em medidas de coerção social, não muito diferentes das que são praticadas ainda hoje (SEVCENKO, 1998). Ao observar a pintura de Claude Monet retratando a paisagem urbana de Paris do século XIX (Figura 2), percebemos o predomínio desta cidade artificial que nos é familiar, criada para ambientar o ideal de progresso, de regularidade social e de controle sob a natureza humana e ambiental.

No final do século XX, além da regulamentação do corpo social, a experiência estética tornou-se a experiência da presença tanto do objeto estético como do sujeito que o percebe. Esta experiência é gratuita e não visa um interesse prático imediato. De acordo com Flores (2014), a estética surge na modernidade como teoria, com a intenção de governar as sensações humanas, onde apenas a razão já não é suficiente para garantir o controle. A

\footnotetext{
7 No período entre 1920 e 1950, a visão eugênica da medicina torna-se influente na definição de normalidades e anomalias corporais, entre aqueles sujeitos mais aptos e inaptos da sociedade, com base em parâmetros racistas, que enfatizam como prejuízo as diferenças físicas entre etnias humanas. E ainda, como se a biologia do corpo fosse um fator fixo, estável; como se a (própria) ideia do corpo perfeito não fosse uma construção cultural. Neste caso, por medidas antropométricas, tornou-se justificável a tendência da época em estabelecer um padrão de configuração corporal para o Ocidente (FLORES, 2007).
}

(c) Urbana: Rev. Eletrônica Cent. Interdiscip. Estud. Cid.

Campinas (SP)

v.7, n.2 [11]

p. $65-85$

ISSN 1982-0569 
concepção artística, neste caso, surge como suporte para a representação social e imagética de um senso estético, político e articulador.

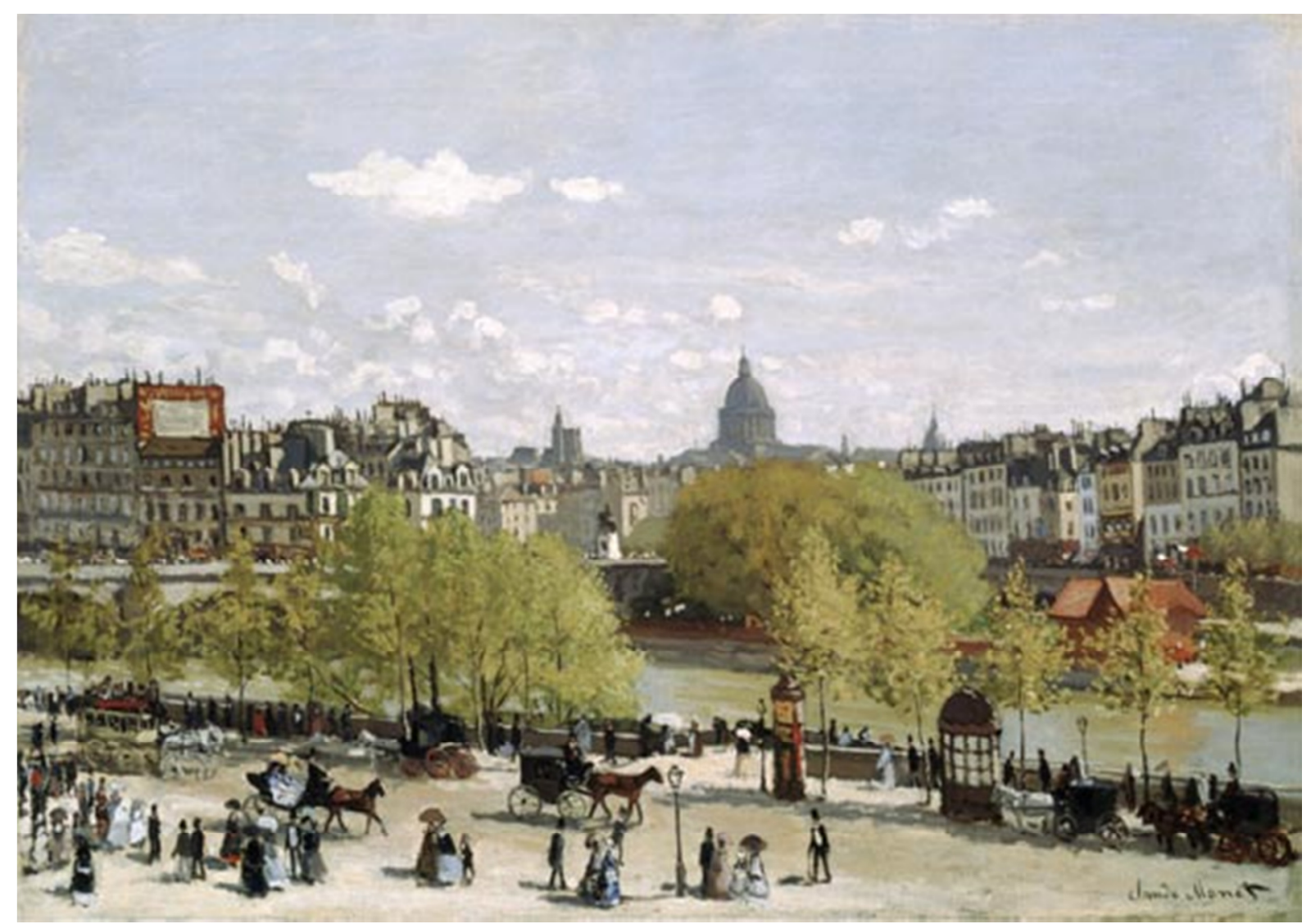

Figura 2 - Paris no século XIX. Pintura de Claude Monet, "Quaid du Louvre", 1867. Regularidade e ordem colocadas em prática com a reforma urbana de Paris promovida pelo Barão Haussman, através dos princípios de uma modernidade idealizada, que mantém sob controle a natureza humana e ambiental. Fonte: <http://www.monetalia.com/paintings/monet-quai-du-louvre.aspx> Acesso em 03 Abr. 2016.

É neste sentido de conformação da subjetividade, que a arte desafia nosso intelecto tanto quanto as nossas capacidades perceptivas e emocionais. Para o filósofo Jacques Rancière (2011), a arte existe pelo enquadramento de regimes de identificação, conferindo especificidade às suas práticas e na associação com diferentes modos de percepção, afetos e padrões de inteligibilidade, enquanto "a estética implica no livre jogo da faculdade intelectual e da faculdade sensível" (RANCIÈRE, 2011, p. 6). Para o autor "a palavra 'estética' não remete a uma teoria da sensibilidade, do gosto ou do prazer dos amadores de arte. Remete, propriamente, ao modo de ser específico daquilo que pertence à arte, ao modo de ser de seus objetos" (RANCIÈRE, 2005, p. 32).

Nestas fundamentações das tradições modernas temos o grande entrave para a ambientação de uma condição humana mais criativa, onde "a regulamentação é inimiga da inventividade, já que só se chega ao novo infringindo regras" (OLIVA, 2005, p. 17). 


\section{3. "O Congresso Futurista" e a Cidade Intersubjetiva}

Ao longo da consolidação do mundo moderno no século $X X$, a arte e o cinema foram dispositivos fundamentais para projetar as expectativas visuais dos empreendimentos futuros, englobando a cidade, o corpo do cidadão e o comportamento social. O processo de imaginação, que surge a partir da arte, possibilita novos modos de gerar o interacionismo simbólico, na maneira como as pessoas criam significados e objetos em suas linhas de ação, normalmente, limitados naquilo que pode ser identificado e reconhecido (BLUMER, 1980).

Apresentando uma nova ordem de significados, a obra cinematográfica "O Congresso Futurista" (FOLMAN et al, 2013) representa uma prospecção avançada do simulacro criado para a cidade espetacular e industrial, que alterou toda a condição material da humanidade a partir do final do século XIX, e pode ser interpretada como uma crítica contra o processo atual de alienação da população. Seja através da paisagem urbana espetacular em metrópoles como Paris, Londres e Nova Iorque, ou na divulgação destes cenários de desejo pela própria indústria de produtos e artigos técnicos do cinema.

O filme [The Congress, 2013] é uma narrativa sobre o aprisionamento da percepção visual e dos desejos humanos através da manipulação química das emoções, em um estado permanente de delírio, como se cada consciência estivesse inserida na criação mental de sua própria heterotopia, enquanto lugares diferentes, particulares, reinterpretados (FOUCAULT, 2013). Nesta montagem ficcional, a linguagem do live-action mistura-se com a linguagem do desenho animado, dando possibilidade para a criação de um mundo irrepresentável, líquido e efêmero enquanto imagem e movimento.

Dirigido pelo israelense Ari Folman, o filme nos permite refletir sobre a espetacularização do mundo virtual e da falsa sensação de liberdade. Misturando drama e ficção, o filme apresenta uma sequência narrativa complexa, onde a utopia de um mundo comum seria complementada por heterotopias, onde cada sujeito pode se aprofundar em seu estado de consciência e significações particulares. Para Foucault (2013), as heterotopias são complexas e não podem ser entendidas de imediato, por serem lugares de múltiplas significações. Por este caráter múltiplo, a heterotopia se torna viável apenas em contextos não hegemônicos, uma vez que, segundo o autor, está baseada no dissenso (FOUCAULT, 2013).

A estória é narrada sob a perspectiva da personagem Robin Wright (mesmo nome da atriz que a interpreta), que vive grandes dilemas: o desprestígio de sua carreira como atriz, a necessidade de garantir seu futuro financeiro e a progressiva debilitação auditiva e visual do filho mais novo, que sofre da Síndrome de Usher. A partir de uma proposta única e rentável, ela concorda assinar um contrato com o Estúdio Miramount em troca da apreensão de sua representação visual e expressões, faciais e corporais. Sua imagem é escaneada e imortalizada para a criação de uma atriz digital idêntica, a ser utilizada no processo de interpretação e narração das futuras estórias de ficção cinematográfica. Nesta apropriação do seu rosto, corpo e lágrimas pelo computador, o Estúdio passa a ter controle sobre sua performance cênica no 
formato digital da atriz, impedindo sua atuação profissional e autonomia física pelas próximas duas décadas. Ao longo do filme, passam-se vinte anos e a atriz, com 66 anos, é convidada a participar da estreia de um dos "seus" filmes no Congresso do Estúdio, onde todos os participantes precisam inalar um produto químico para se inserir no lançamento desta nova realidade virtual, onde acontecerá o Congresso. Este nível de realidade é representado em desenho animado. A partir desta sequência, tudo se torna uma animação e cada pessoa tem a possibilidade de se transformar na imagem que quiser à medida que inalam outras fórmulas químicas. Durante o Congresso acontece uma revolução, que mantém a personagem Robin e boa parte da população presos neste simulacro totalizador, dentro da relativa relação desencadeada entre tempo e lembranças da realidade live-action.

É neste enredo de transformações onde a simulação da realidade exemplifica a presença de diversos tipos de sujeitos, que rompem com a regulamentação do gênero e da sexualidade como indivíduos e, aos poucos, alteram o âmbito coletivo e a configuração dos lugares. A formação de perfis ambíguos, ao longo da animação do filme, poderia estar relacionada com sujeitos intersexuais e transexuais, caracterizando indivíduos que mesclam as categorias do sexo biológico e das identidades de gênero, tornando questionável o princípio que sustenta a heteronormatividade, na visão de um mundo binário entre homens e mulheres (FERIA, 2014).

Com a intenção de desestabilizar o gênero e o sexo, enquanto categorias fixas e imutáveis, a teoria queer é uma reavaliação crítica das políticas de identidades. Além de contestar a pressuposição de que a heterossexualidade seria a ordem natural, o queer evidencia as injustiças e violências praticadas contra identidades e corpos que fogem das normas e das moralidades estabelecidas como adequadas (MISKOLCI, 2014). Inclusive, ampliando este conceito, podemos considerar os princípios de cuidado dos corpos para outras espécies, além da humana (BUTLER, 2015c).

Nesta relação com princípios éticos, o queer se torna ainda mais complexo, englobando tanto o gênero quanto a raça, o sexo, a orientação sexual, a classe social e a linguagem, como aspectos performativos e particulares, que nos permitem a compreensão dos sujeitos sociais. Esta abertura para a compreensão das particularidades sem condicioná-las torna a teoria queer uma tática de resolução de conflitos sem estabelecer comprometimento na formação de uma identidade ou categoria. Este estranhamento constante para a definição do queer nos encaminha para um processo similar na criação de um organismo ciborgue. Ciborgues no sentido descrito por Donna Haraway (2009), enquanto organismos híbridos, presos tanto na imaginação quanto na realidade viável do corpo, na fronteira entre o humano e o não humano e sem estabelecer uma identidade fixa vinculada ao binarismo dos gêneros.

Ilustrar este organismo queer e ciborgue por meio de uma linguagem artística e vinculada à intersubjetividade humana é parte da contribuição do filme. Interpretando a arte em uma perspectiva queer, Rosa Maria Blanca (2011) nos traz o questionamento da força do 
corpo como imagem e o seu desencadeamento subjetivo no espaço onde está inserido. Para a autora o queer trabalha atravessando e produzindo realidades mediante imagens e manifestos visuais, sem uma associação direta com a arte erótica. Na formulação de sua metodologia de pesquisa, a autora propõe desenvolver uma linguagem pela prática da arte, "mediante conceitos operativos de ambiguidade, fetichismo, manifesto e desafio" (BLANCA, 2011, p. 28).

Seguindo esta metodologia, a narrativa artística apresentada em "O Congresso Futurista" parece ilustrar esta ideia associada ao mundo onírico, onde a utopia e o desejo estão imediatamente associados. Seria como se a percepção comum e padronizada, na interpretação da realidade, fosse reduzida para abrir possibilidades aos interesses particulares. Neste paradoxo entre a imaginação e a realidade, a animação retratada pelo filme apresenta referências espaciais com base na categoria de espaços reais, reinterpretando a cidade de Nova Iorque na simbiose deste processo de transformações das identidades. Ou na criação de uma natureza exótica, por onde atravessam os personagens Robin Wrigth e Dylan Truliner $^{8}$ durante uma das passagens do filme, até chegarem à Nova Iorque.

Nesta representação de cidade pela referência no filme é onde estão as melhores oportunidades de libertar a mente dos pensamentos comuns. De acordo com a narração da personagem Robin Wright: "Nova Iorque agora é uma cidade de jardins suspensos que chegam ao céu. As cores desordenadas nos atingem cheias de força e as pessoas são tão lindas, tão jovens e radiantes, emitindo serenidade, beleza e sexualidade" (FOLMAN et al, $2013,1: 16: 00)$. Na visão futurista, pela estética da animação do filme, torna-se singular a representação de um ambiente de liberdades mentais, onde cada indivíduo desconstrói sua própria identidade, reconstruindo imagens que não seguem uma única linha de pensamento.

Esta indefinição de identidades no contexto coletivo torna-se um simulacro interessante no filme. A presença de sujeitos andrógenos, heróis, místicos, extravagantes e alienígenas, expressando ambiguidades de gênero e de proporções corporais repercutem em transformações na própria configuração do lugar. Estes aspectos podem ser observados através da Figura 3 e em contraposição à Figura 1, que representa o perfil padrão e binário, para uma cidade ordenada e sob controle.

\footnotetext{
${ }^{8}$ Dylan Truliner é outro personagem, que acompanha a narrativa na segunda parte do filme e imprime um caráter romântico para a estória.
} 


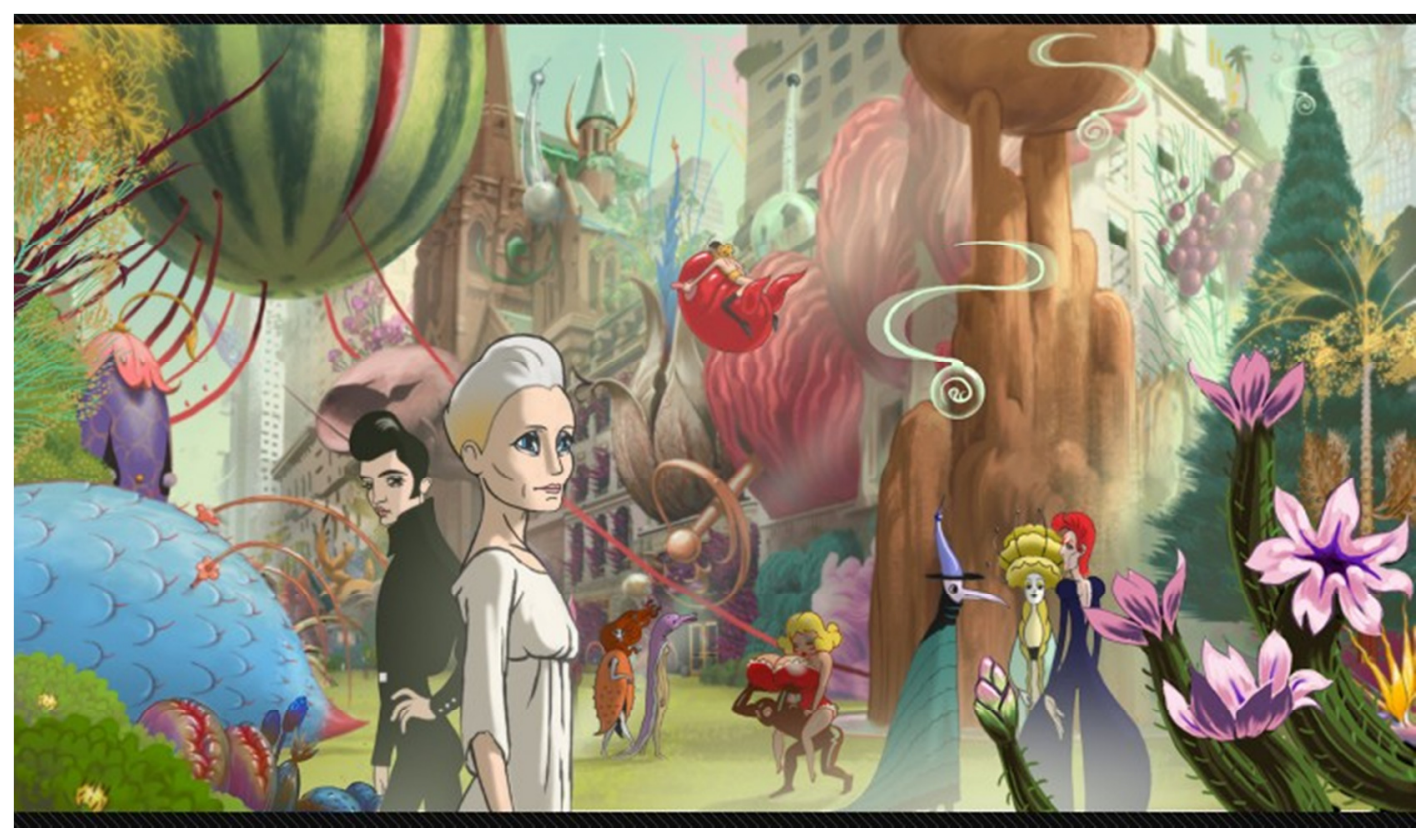

Figura 3 - Cena de Robin Wright em Nova Iorque, no Filme "O Congresso Futurista", de 2013.

Personagem envolvida por perfis sociais ambíguos, representando personalidades, seres andrógenos, híbridos e extravagantes, junto ao dinamismo dos elementos de composição do lugar, que tornam a cidade um grande organismo de interações simultâneas.

Fonte: <http://www.cinemadebuteco.com.br/wp-content/uploads/2014/11/adapta\%C3\%A7\%C3\%B5escongresso-futurista.jpg > Acesso em 03 Abr. 2016.

Todos os aspectos apresentados na parte da animação, em relação às dinâmicas espaciais e a passagem do tempo, são relativizados. Depois que os personagens passam muito tempo inseridos nesta percepção digital profunda, todas as referências adquiridas na realidade live-action se desfazem. Neste contexto "não há mais ego graças à química que fomos submetidos", de acordo com o relato do personagem Dylan. "Não há mais ego, nem competição, nem violência, nem fraco e nem forte. Nem segredos. Todos são o que são. Todos são o que querem ser. Enquanto consomem sua nova personalidade, eles espalham no ar aqueles feromônios em sua mente, traduzidos para uma imagem" (FOLMAN et al, 2013, $1: 16: 00)$.

A animação apresentada no longa-metragem revela possibilidades de interpretação lúdica sobre a existência humana, sem o propósito de atingir uma explicação coerente com as expectativas da realidade. A narrativa é uma aventura por novos caminhos na interpretação da condição humana, envolvendo a sexualidade, a identidade e a expressão de gênero. Estas categorias sociais tornam-se relativas e flexíveis através do desenho animado, que permite questionar os limites tênues entre realidade e imaginação. Como se a relatividade pudesse ser estimulada pela desconstrução das regras visuais, normalmente, estabelecidas pela linguagem fotográfica e pelo live-action, definindo um simulacro fora das regras da física e da materialidade. 
Ao contrário deste contexto de relatividades do filme, as Exposições Universais em Paris, durante o Segundo Império [1852-1870], procuravam celebrar o sólido nascimento do moderno, definindo-se como lugares de peregrinação para o fetiche da mercadoria. Uma estrutura que iniciava o processo de controle e disciplina sobre as atividades públicas da população. As exposições atraiam multidões de províncias e do exterior da França. Este movimento estimulava o consumo e o turismo na capital. Nesta nova relação com o espaço público, no final do século XIX, a relação da população com o consumo se expressava pela necessidade de representar-se socialmente como consumidor, tendo o espaço público como ponto de encontro e auto-exibição. Este aspecto foi bastante explorado junto às mulheres, de maneira que, o consumismo permitiu uma nova inserção delas no espaço público: local de exibição das mercadorias e do comércio, revestido em uma aura de desejo e trocas sexuais. "A transformação dos parques em locais de socialização e lazer também contribuiu para estimular uma forma extrovertida de urbanização, que destacava a exibição pública da opulência privada" (HARVEY, 2015, p. 288). As divisões de classe se destacam nesta representação social do público consumidor. A própria relação do mercado liberal define o contraste, entre classes sociais e espaços urbanos. Lugares onde as máscaras sociais tornam-se mais importantes do que a realidade de vida, onde "a vida cotidiana passa a imitar as fachadas exibidas no baile de máscaras ou durante o Carnaval" (HARVEY, 2015, p. 295).

Diferente da cidade espetacular onde a atenção de todos está direcionada para eventos pontuais, na virtualidade retratada pelo filme, os estímulos e as transformações materiais podem seguir caminhos particulares de acordo com os interesses de cada sujeito, quando se aprofunda em suas sensações e desejos. Dentro desta dinâmica de particularidades indefinidas, a cidade ficcional de Nova Iorque, em "O Congresso Futurista", apresenta uma contínua alteração da paisagem urbana na medida em que a animação torna-se a realidade líquida, abrigando todos os estados de consciência sem alterar suas singularidades. É nesta relação de profundidade com a intersubjetividade da população que os efeitos da regulamentação perdem controle sobre os desejos de cada pensamento, relativizando as escolhas na interpretação de realidade comum.

Na relação entre os personagens do filme e o ambiente da encenação, o que nos interessa destacar é a reconstrução da emblemática Nova Iorque, redesenhada para corresponder a este estado de criação indefinida, na relação intersubjetiva de tempo e espaço, sem atender demandas prévias estabelecidas por comportamentos e categorias sociais. Neste cenário, Nova Iorque apresenta indefinições quanto aos materiais que compõem seus edifícios e rearranjos nos elementos de sua configuração espacial. É uma combinação de formas orgânicas e inanimadas, estáticas e dinâmicas, naturais e artificiais. Elementos decorativos somam-se na composição de prédios misturados a elementos vegetais ou arranjos ecléticos, como se houvesse uma mistura do repertório da cidade antiga, em referência a realidade 
física, com outras possibilidades de definição dos objetos e da estrutura urbana a serem experimentadas nesta permanente utopia digital.

Quando os personagens principais chegam à Nova Iorque a paisagem da cidade já não tem o mesmo efeito espetacular da cidade de Paris do século XIX, com suas grandes avenidas implantadas durante a reforma de Haussmann. No filme, a cidade de concreto é substituída gradualmente por uma natureza exuberante e disforme, como podemos observar na Figura 4. Elementos orgânicos se sobrepõem na composição dos prédios e nos vazios urbanos. As áreas livres demarcam o lugar dos encontros e da exposição pública entre figuras ciborgues, misturando a identidade de celebridades, corpos eróticos, roupas extravagantes e comportamentos para além da uma vaga ideia de natureza humana vinculada aos parâmetros da heteronormatividade.

$\mathrm{Na}$ interpretação desta simbiose, as dinâmicas da performatividade de gênero e a representação virtual do corpo podem ser utilizadas como manifestação artística ou servir como origem da reflexão da nossa existência física mutável. Assim, a ideia de corpo pode ser objeto tanto de desejo quanto fonte de prazeres. A própria relação de dominação e submissão já não distingue a ideia do corpo do outro a ser controlado, ou do próprio corpo entregue como objeto do desejo alheio. Uma manifestação discreta da estetização do amor infinito que toma o corpo de outro como "um ato soberano do desejo pela beleza, que dificilmente disfarça sua tirania" (JEUDY, 2002, p. 13).

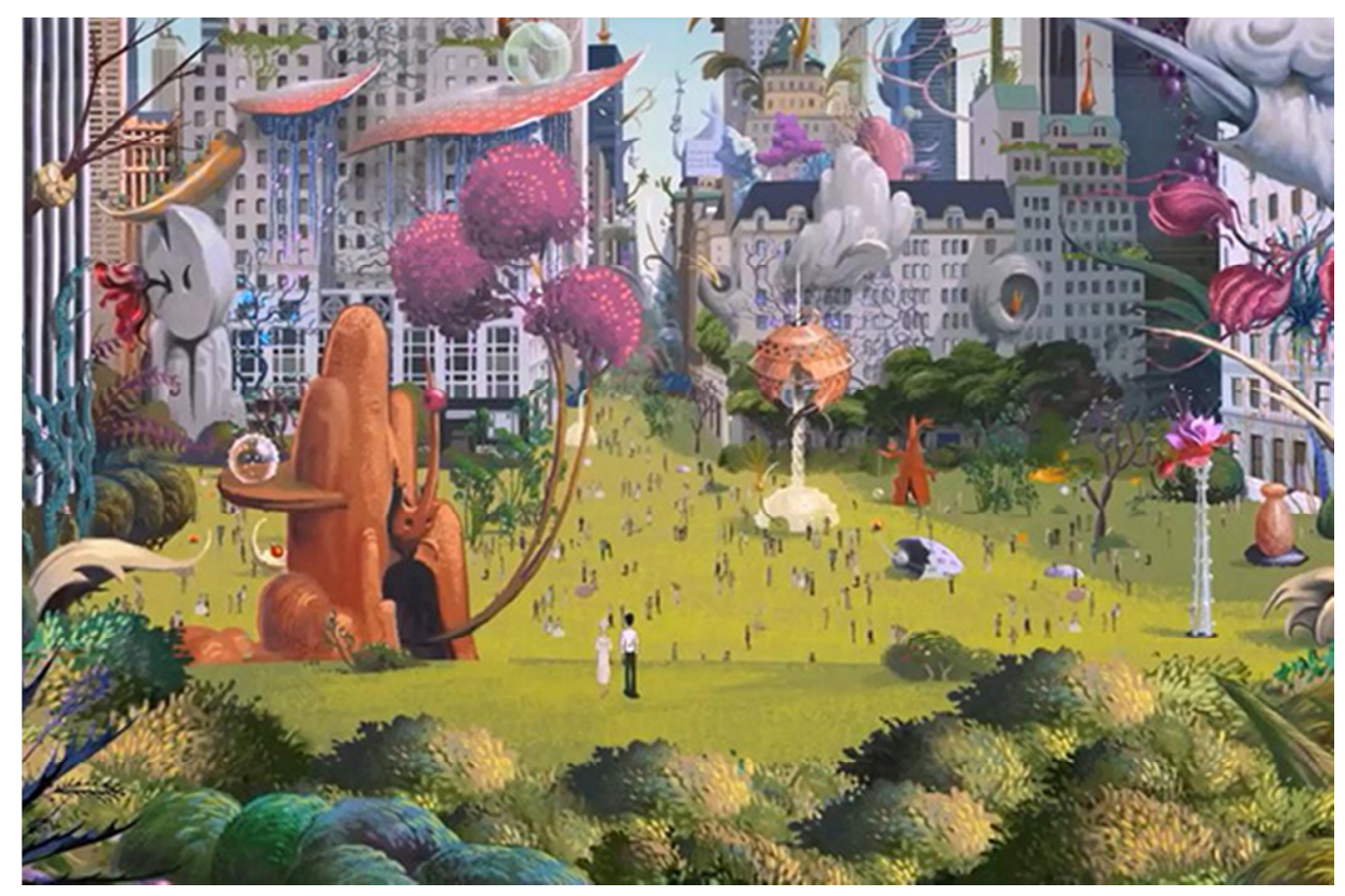

Figura 4 - Vista geral da chegada dos personagens a Nova Iorque, no Filme "O Congresso Futurista". Configuração espacial que explora a natureza selvagem, na formação aleatória e efêmera dos elementos de ornamentação. Uma concepção de cidade que foge do ordenamento controlado e padrão quando comparada aos princípios da reforma urbana de Paris, no século XIX. Fonte: <http://urxxblog.blogspot.com.br/> Acesso em 25 Ago. 2015. 
O casal formado por Robin e Dylan caminha como flâneurs entre a multidão nos espaços da cidade, ou alcançam a liberdade de voar sobre os prédios e sair rapidamente das áreas densas e centrais. Neste contexto de profundidades a partir dos sentimentos individuais, não existem limites para a transformação do corpo e a realização dos desejos.

A figura mítica do flâneur, destacada por Charles Baudelaire no século XIX, define um sujeito de multidões, que precisa do espaço livre sem perder sua privacidade, na busca errante por uma experiência não planejada para a compreensão particular e descomprometida com a organização do espaço urbano (JACQUES, 2012). Por isso, o flâneur está no processo de formulação de subjetividades, sonhos e desejos, marcados em narrativas urbanas através das experiências de caminhar com lentidão e incorporar sensações pela inserção do corpo no ambiente citadino. Na referência apresentada por Jacques (2012, p. 21), as narrativas errantes enfatizam as questões da experiência do corpo e da alteridade na cidade, "reafirmando a enorme potencia da vida coletiva, uma complexidade e multiplicidade de sentidos" não mais encontrados nas imagens publicitárias da cidade espetacular contemporânea.

Apresentando outro ponto de vista, Paul Preciado (2011) considera válido a potência de atuações políticas da multidão a partir do queer. Para o autor, a noção de multidão queer é um reconhecimento coletivo da diferença latente dos sujeitos anormais, deixando de ser periférica e restrita aos guetos para se tornar visível no espaço urbano. O resultado da ação desta multidão queer, de acordo com Preciado (2011), seria a desterritorialização do espaço urbano e corporal, resistindo aos processos de normalização. Este efeito torna-se nítido na maneira como o filme desenvolve sua narrativa de transformações do corpo dos figurantes e do ambiente de interações sociais, em especial, quando retrata a cidade de Nova Iorque. Esta cidade icônica, que também se transforma em um espaço flexível na conformação dos sujeitos ciborgues ali presentes.

A mutação dos corpos e das práticas sexuais indicados na multidão futurística de Nova Iorque é uma ideia visual também associada aos princípios de uma sociedade contra-sexual, definida em outra publicação de Preciado (2002). O conceito da contra-sexualidade dedica-se a desconstrução sistemática das práticas sexuais e do sistema de gênero essencializados pelo discurso heterossexista e proclama a equivalência de todos os corpos-sujeitos comprometidos com a busca do prazer-saber. Para o autor, a história natural da sociedade humana deveria ser descrita como a história das tecnologias, sendo a compreensão de sexo e gênero inscritas em um sistema tecnológico complexo "como efeito de negociação permanente das fronteiras entre humano e animal, corpo e máquina" (PRECIADO, 2002, p. 20).

Estes conceitos atravessam a perspectiva artística apresentada pelo filme, onde "a arte parece ser um campo de referências para princípios imagináveis de outras linguagens de conhecimento, da subjetividade e do desejo" (BLANCA, 2011, p. 48). Através da poética 
apresenta pelo filme, interpretamos possibilidades para a condição dos processos regulatórios sobre a instabilidade do corpo, agindo discursivamente através de práticas performativas, que também se realizam em função de uma adequação visual em um contexto histórico e cultural.

Em contraposição, na relação entre a linguagem, o corpo e o lugar, que herdamos da modernidade, definem-se as disciplinas de uma contingência histórica e material, que nos impede de ir além da compreensão convencional da dimensão urbana, do impensável para a representação singular do corpo e da identidade. Portanto, a estabilidade na concepção urbana atual representa as intenções de controle, segregação e permanência dos parâmetros heterossexuais, e não se predispõe aos processos de transformação contínua e qualitativa, como parte das dinâmicas envolvidas nas relações humanas e na paisagem urbana.

\section{Considerações Finais}

Não muito diferente do que aconteceu na Paris do século XIX, no filme "O Congresso Futurista" a ideia da suposta liberdade individual também representa um simulacro, que serve para esconder o real aprisionamento do corpo e da condição de vida social. Ao final do filme, este simulacro do desenho animado se revela uma prisão mental e coletiva, que esconde as mazelas e a melancolia da condição humana. Mas, por que uma representação utópica de liberdade precisa ser convertida em distopia ao final da narrativa? Será esta narrativa uma amostra da estrutura do discurso que nos tornar mais recilientes à condição inevitável da modernidade? Esta condição, imposta pelo passado, é mais confortável do que a imprevisibilidade do futuro?

O reforço das categorias sociais é uma herança das medidas de controle da sociedade industrial. Na medida em que categorias e estigmas são mantidos, definem-se referências de distinção para o que deve ser significativo na constituição das identidades, das moralidades e dos objetos na vida urbana.

Pensar em maneiras de romper com os significados da visão heteronormativa é lidar com as incertezas. Diferente da insegurança e do medo, que abalam os meios de sobrevivência, a incerteza gerada no campo epistemológico refere-se a outros meios de pensar a realidade, não apenas baseando-se na razão e na sua eterna busca pela verdade.

Na visão de Heidegger (1997), quando aponta que nem tudo o que está correto representa a verdade, podemos considerar que a arte tanto pode impregnar técnicas de regulamentação para servir de referência ao ideal da forma do corpo e das sensações, quanto tornar possível a proteção da essência do pensamento autônomo e crítico, que desafia os pressupostos da modernidade. O exercício deste pensamento insubordinado, poético e questionador define a base para encarar as incertezas e extrair uma nova significação ontológica para a relação entre o corpo, o gênero e o espaço. 
De acordo com Butler (2002), a significação que é dada ao corpo estabelece a sua materialidade. Por mais que a autora trate das relações intrapsíquicas para interpretar a condição da identidade pela performatividade de gênero, acreditamos ser possível ampliar este campo de reflexão, da materialidade sob a influência da identidade, para a dimensão física que vai além da superfície externa do corpo materializado pela reificação da perfomatividade. Além deste corpo está o espaço que o circunscreve e os objetos que lhe dão apoio, representando e reafirmando as condições performativas vinculadas as condições técnicas (externas ao corpo), que amplia a representação deste corpo na vinculação com o discurso hegemônico. É em função deste discurso normatizado, assimilado pela performatividade do corpo, que a cidade torna-se uma contingência da identidade de gênero e da sexualidade.

Portanto, em uma sociedade que desrespeita a livre manifestação identitária e política, estabelecendo controle para as sexualidades e promovendo medidas corretivas aos corpos que não atendem a um perfil social - é a mesma sociedade que estabelece modelos de reforma urbana com base na funcionalidade e na eficiência dos meios de produção, sem atender aos interesses sociais e humanos como prerrogativa.

Por mais incomoda que pareça, esta descrição representa a realidade social e urbana que herdamos da modernidade. A mesma herança reificada pela performatividade heterossexual compulsória, que precisa ser repetida constantemente e nunca é completa na materialização particular do corpo, para atender ao ideal estabelecido pela norma, devido à imposição de sua materialidade padrão.

A possibilidade de transformar este lugar convencional, permitindo explorar o potencial da expressão do gênero e da sexualidade e garantindo o respeito aos corpos de cada indivíduo, como foi exemplificado a partir do filme, torna-se uma hipótese improvável enquanto transposição de categorias a partir de uma realidade já estruturada. Entretanto, com base na teoria queer, consideramos que a contestação das regras não se faz pelo enfrentamento direto contra as atuações e encenações de uma realidade hegemônica ou contra uma estética da modernidade. O processo de transformação potencial parece se infiltrar no intervalo sutil de distinção entre o início e o fim da repetição dos atos performativos. São nestes detalhes do hábito, do gesto, do movimento único do corpo e das relações interpessoais, elevando o potencial estético a ser incorporado nesta singularidade, que uma consciência cuidadosa e sensível pode alterar a superfície do caminho, em simbiose com o seu deslocamento, ao longo de tantas possibilidades na conformação do percurso.

\section{Referências}


AGAMBEN, Giorgio. O Homo Saccer: o poder soberano e a vida nua I. $2^{a}$ ed., Belo Horizonte: Editora UFMG, 2002, p. 125-166.

BLANCA, Rosa Maria. Arte a Partir de uma Perspectiva Queer/Arte Desde Lo Queer. Tese. Programa de Pós-graduação Interdisciplinar em Ciências Humanas. Florianópolis: UFSC, 2011. Disponível em <http://www.tede.ufsc.br/teses/PICH0099-T.pdf> acesso em abril de 2016.

BLUMER, Herbert. A Natureza do Interacionismo Simbólico. In: MORTENSEN, C. David. Teorias da Comunicação: textos básicos. São Paulo: Editora Mosaico, 1980, pp. 119-138.

BUTLER, Judith. Quadros de Guerra: quando a vida é passível de luto? Tradução Sérgio Tadeu de Niemeyer Lamarão e Arnaldo Marques da Cunha. $1^{a}$ ed. Rio de Janeiro: Civilização Brasileira, 2015a.

BUTLER, Judith. Problemas de Gênero: feminismo e subversão da identidade. Tradução Renato Aguiar. $8^{a}$ ed. Rio de Janeiro: Civilização Brasileira, 2015b.

BUTLER, Judith. Entrevista. Folha de São Paulo, 20 de setembro de 2015c. Disponível em <http://www1.folha.uol.com.br/ilustrissima/2015/09/1683172-sem-medo-de-fazer-generoentrevista-com-a-filosofa-americana-judith-butler.shtml> acesso em abril de 2016.

BUTLER, Judith. Cuerpos que Importan: sobre los límites materiales y discursivos del "sexo". $1^{a}$ ed. Buenos Aires: Paidós, 2002.

CALABI, Donatella. História do Urbanismo Europeu: questões, instrumentos, casos exemplares. Tradução de Marisa Barda e Anita Di Marco. São Paulo: Perspectiva, 2015.

CHOAY, Françoise. A Regra e o Modelo: sobre a teoria da arquitetura e do urbanismo. Tradução Geraldo Gerson de Souza. 2a ed. São Paulo: Perspectiva, 2010.

FERIA, Rafael Cárceres. (Professor visitante CNPq/FAPESC; Universidade Pablo de Olavide, Departamento de Antropologia Social, Psicologia Básica e Saúde Pública. Sevilla-ES). Aulas proferidas na disciplina de Tópicos Especiais em Sexualidades. Programa Interdisciplinar em Ciências Humanas da Universidade Federal de Santa Catarina. Florianópolis: UFSC, Ago-Set. 2014.

FLORES, Maria Bernardete Ramos. Androginia e Surrealismo a Propósito de Frida e Ismael velhos mitos: eterno feminino. In: Revista Estudos Feministas. Florianópolis, 22(3): Set-Dez de 2014, pp. 815-837.

FLORES, Maria Bernardete Ramos. Tecnologia e Estética do Racismo: ciência e arte na política da beleza. Chapecó: Argos, 2007.

FOLMAN, Ari. ELBAUM, Diana. GRUMBACH, David. MANSURI, Eitan. SAMUELS, Jeremiah. $O$ Congresso Futurista. [Filme-vídeo] Israel: Bridgit Folman Films Gang, 2013, DVD, 122 minutos, Dolby Digital 5.1.

FOUCAULT, Michel. História da Sexualidade 1: vontade de saber. Tradução de Maria Thereza da Costa Albuquerque e J. A. Guilhon Albuquerque. 1a Ed. São Paulo: Paz e Terra, 2014.

FOUCAULT, Michel. O Corpo Utópico; As Heterotopias. Posfácio de Daniel Defert; Tradução de Salma Tannus Muchail. São Paulo: n-1 Edições, 2013.

FOUCAULT, Michel. Segurança, Território e População: curso dado no College de France (19771978). Tradução Eduardo Brandão; revisão da tradução Claudia Berliner. São Paulo: Martins Fontes, 2008.

FOUCAULT, Michel. Polêmica, Política, Problematizações. In: Ditos e Escritos. Volume V. Ética, Sexualidade, Política. Rio de Janeiro: Forense Universitária, 2004, pp. 225-233.

GOMES, Anderson Soares. Mulheres, Sociedade e Iluminismo: o surgimento de uma filosofia protofeminista na Inglaterra do século XVIII. In: Revista Matagra. V. 18, No 9. Rio de Janeiro, jul-dez 2011, pp. 31-51. 
HARAWAY, Donna J. Manifesto Ciborgue: ciência, tecnologia e feminismo-socialista no final do século XX. In: TADEU, Tomaz. (Org. e Trad.). Antropologia do Ciborgue: as vertigens do póshumano. $2^{\mathrm{a}}$ ed. Belo Horizonte: Autêntica Editora, 2009, pp. 33-118.

HARVEY, David. Paris: capital da modernidade. $1^{\text {a }}$ Ed. São Paulo: Boitempo, 2015, pp. 281299.

HEIDEGgER, Martin. A Questão da Técnica. São Paulo: USP, 1997, pp. 40-93.

JACQUES, Paola Berenstein. Elogio aos Errantes. Salvador: EDUFBA, 2012.

JACQUES, Paola Berenstein. Errâncias Urbanas: a arte de andar pela cidade. São Paulo:

ArqTexto 7, 2005, pp. 16-25.

JEUDY, Henri-Pierre. O Corpo como Objeto de Arte. Tradução Tereza Lourenço. São Paulo: Estação Liberdade, 2002.

LOURO, Guacira Lopes. "Foucault e os Estudos Queer". In: RAGO, Margareth. VEIGA-NETO, Alfredo (Orgs.). Para a uma Vida não-Facista. Belo Horizonte: Autêntica Editora, 2009, pp. 135-142.

MASSEY, Doreen. Space, Place and Gender. Minneapolis: University of Minnesota Press, 1994. MISKOLCI, Richard. Crítica à Hegemonia Heterossexual. In: Revista Cult. 193. Ano 17. Agosto de 2014, p. 33-35.

MUNFORD, Lewis. A Cidade na História: suas origens, transformações e perspectivas. Tradução Neil R. da Silva. 5a Ed. São Paulo: Martins Fontes, 2008.

OLIVA, Alberto. Anarquismo e Conhecimento. Rio de Janeiro: Jorge Zahar Ed., 2005.

PESAVENTO, Sandra Jatahi. O Imaginário da Cidade: visões literárias do urbano - Paris, Rio de Janeiro, Porto Alegre. Porto Alegre: Ed. UFRGS, 1999.

PRECIADO, Paul. Multidões Queer: notas para uma política dos "anormais". In: Revista Estudos Feministas. Tradução de Cleiton Zóia Münchow e Viviane Teixeira Silveira. 19(1). Florianópolis, jan-abr, 2011 [2003], pp. 11-20.

PRECIADO, Paul. Manifesto Contra-Sexual. $1^{\text {a }}$ ed. Madrid: Editoral Opera Prima, 2002.

RANCIÈRE, Jacques. O que significa Estética. In: Projeto YMAGO [internet]. KKYM, Lisboa, 2011. Disponível em <http://cargocollective.com/ymago/Ranciere-Txt-2> acesso em abril de 2016.

RANCIÈRE, Jacques. A Partilha do Sensível: estética e política. Tradução de Mônica Costa Netto. São Paulo: EXO experimental org.; Ed. 34, 2005.

SÊGA, Rafael Augustus. Os Melhoramentos Urbanos como Estratégias de Dominação Social. In: Anos 90. N. 14. Porto Alegre, Dez. 2000, pp. 218-230.

SENNETT, Richard. Carne e Pedra: o corpo e a cidade na civilização ocidental. Tradução de Marcos Aarão Reis. 3a Edição. Rio de Janeiro: Record, 2003.

SEVCENKO, Nicolau. A Capital Irradiante: técnicas, ritmos e ritos do Rio. In: SEVCENKO, Nicolau (Org.). História da Vida Privada no Brasil. São Paulo: Companhia das Letras, 1998, pp. 513-619.

SIMMEL, Georg. A Metrópole e a Vida Mental. In: VELHO, Otávio Guilherme (Org.). O Fenômeno Urbano. 4a Ed. Rio de Janeiro: Zahar, 1979, pp. 11-25.

SUÁREZ, Rafael Ernesto Sánchez. La Identidad Queer del Espacio en la Ciudad de México. In: Primer Congreso Internacional sobre Género y Espacio. Abr.2015, Universidad Autonoma del México. Ciudad del México, DF, 2015, pp. 193-210.

TRINDADE, Thiago Aparecido. Direitos e Cidadania: reflexões sobre o direito à cidade. In: Lua Nova. 87. São Paulo, 2012, pp. 139-165. 